\title{
Optimization of culture conditions for phosphate solubilizing by Acinetobacter calcoaceticus YC-5a using response surface methodology
}

\author{
D. D. Fan ${ }^{1,3 \star}$, Y. X. Ren ${ }^{1,3}$, X. L. Zhu ${ }^{2,3}$, P. Ma ${ }^{1,3}$ and L. H. Liang ${ }^{2,3}$ \\ ${ }^{1}$ Shaanxi Key Laboratory of Degradable Biomedical Materials, School of Chemical Engineering, Northwest University, \\ Taibai North Road 229, Xi'an, Shaanxi 710069, China. \\ ${ }^{2}$ School of Urban and Environmental Sciences, Northwest University, Xi'an 710127, China. \\ ${ }^{3} \mathrm{R} \& \mathrm{D}$ Center of Fermentation Engineering and Biomaterials Technology of Shaanxi Province, Northwest University, \\ Xi'an 710069, China. \\ Accepted 26 August 2011
}

\begin{abstract}
Response surface methodology was employed to optimize the composition of medium for phosphate solubilization by Acinetobacter calcoaceticus YC-5a, which is less well known as phosphate solubilizing plant-associated bacteria. $\left(\mathrm{NH}_{4}\right)_{2} \mathrm{SO}_{4}, \mathrm{Ca}_{3}\left(\mathrm{PO}_{4}\right)_{2}$ and $\mathrm{KCl}$ were found to have significant effects on phosphate solubilization by the Plackett-Burman design. The steepest ascent method was used to access the optimal region of the medium composition, followed by an application of response surface. The analysis revealed that the optimum values of the tested variables were $\left(\mathrm{NH}_{4}\right)_{2} \mathrm{SO}_{4} 0.2 \mathrm{~g} / \mathrm{L}, \mathrm{Ca}_{3}\left(\mathrm{PO}_{4}\right)_{2}$ $12.98 \mathrm{~g} / \mathrm{L}$ and $\mathrm{KCl} 0.49 \mathrm{~g} / \mathrm{L}$, respectively. Phosphate solubilization of $747.72 \mathrm{mg} / \mathrm{L}$, which was in agreement with the prediction, was observed in verification experiment. In comparison to the original level (405.4 mg/L), 1.83-fold increase had been obtained.
\end{abstract}

Key words: Phosphate solubilizing, Acinetobacter calcoaceticus, medium optimization, response surface.

\section{INTRODUCTION}

Phosphorus $(\mathrm{P})$ is one of the major plant nutrients limiting plant growth. Most agricultural soils contain large reserves of phosphorus, a considerable part of which has accumulated as a consequence of regular applications of P fertilizers (Richardson et al., 1994). However, a large portion of soluble inorganic phosphate applied to soil as chemical fertilizer is rapidly immobilized soon after application and becomes unavailable to plants (Dey, 1988). Thus, the release of insoluble and fixed forms of $P$ is an important aspect of increasing soil $P$ availability. Phosphate-solubilizing bacteria (PSB) are well known to promote plant growth because of their ability to convert insoluble form of $P$ to soluble form that can be readily taken up by the plant roots.

Various kinds of bacteria (Rodriguez and Fraga, 1999;

${ }^{\star}$ Corresponding author. E-mail: fandaidi@nwu.edu.cn. Tel: +86 2988305118.
Harris et al., 2006; Perez et al., 2007) and fungi (Whitelaw, 1999; Wakelin et al., 2007) have been isolated and characterized for their ability to solubilize unavailable reduced phosphorus to available forms. Nevertheless, very few studies have reported strains of Acinetobacter as phosphate solubilizing plant-associated bacteria (Kuklinsky-Sobral et al., 2004), Acinetobacter is a ubiquitous bacterial genus widely distributed in soil and water environments, however, their role in the soil P cycle is less well known.

In this study, Acinetobacter calcoaceticus YC-5a, which showed a strong phosphate solubilizing activity was isolated from rhizospheric soil of maize in Northwestern China. This work was to apply the Plackett-Burman design, followed by the paths of steepest ascent and response surface methodology to optimize the culture medium composition for phosphate solubilization by $A$. calcoaceticus YC-5a.The physiology of phosphate solubilization has not studied thoroughly (Rodriguez and Fraga, 1999) and the optimization of $\mathrm{P}$ solubilizing by $A$. 
Table 1. The Placket-Burman design variables (in coded levels) with soluble phosphate as response.

\begin{tabular}{|c|c|c|c|c|c|c|c|c|c|c|}
\hline \multirow{2}{*}{ Run } & \multicolumn{9}{|c|}{ Variable levels } & \multirow{2}{*}{ Soluble P (mg/L) } \\
\hline & $x_{1}$ & $X_{2}$ & $X_{3}$ & $X_{4}$ & $X_{5}$ & $X_{6}$ & $X_{7}$ & $X_{8}$ & $X_{9}$ & \\
\hline 1 & + & - & + & - & - & - & + & + & + & 624.3 \\
\hline 2 & + & + & - & + & - & - & - & + & + & 256.3 \\
\hline 3 & - & + & + & - & + & - & - & - & + & 453.6 \\
\hline 4 & + & - & + & + & - & + & - & - & - & 492.3 \\
\hline 5 & + & + & - & + & + & - & + & - & - & 336.4 \\
\hline 6 & + & + & + & - & + & + & - & + & - & 506.1 \\
\hline 7 & - & + & + & + & - & + & + & - & + & 484.8 \\
\hline 8 & - & - & + & + & + & - & + & + & - & 550.3 \\
\hline 9 & - & - & - & + & + & + & - & + & + & 368.6 \\
\hline 10 & + & - & - & - & + & + & + & - & + & 439.7 \\
\hline 11 & - & + & - & - & - & + & + & + & - & 393.7 \\
\hline 12 & - & - & - & - & - & - & - & - & - & 373.8 \\
\hline
\end{tabular}

calcoaceticus species has not yet been in full detail. Therefore, the aims were to gather some physiological information about the solubility mechanisms, thus hoping to throw some light upon the matter.

\section{MATERIALS AND METHODS}

\section{Microorganism and medium}

The strain $A$. calcoaceticus $\mathrm{YC}-5 \mathrm{a}$ maintained at $-80^{\circ} \mathrm{C}$ in peptone water medium containing $20 \%$ glycerol.

\section{Analytical method}

Solubilization of $\mathrm{P}$ by $A$. calcoaceticus $\mathrm{YC}-5$ a were estimated using insoluble $\mathrm{Ca}_{3}\left(\mathrm{PO}_{4}\right)_{2}$ in National Botanical Research Institute's Phosphate (NBRIP) broth medium (Nautiyal, 1999). The composition of the medium was (g/L): glucose, $10 ; \mathrm{Ca}_{3}\left(\mathrm{PO}_{4}\right)_{2}, 5$; $\mathrm{MgCl}_{2} \cdot 6 \mathrm{H}_{2} \mathrm{O}, 5 ; \mathrm{MgSO}_{4} \cdot 7 \mathrm{H}_{2} \mathrm{O}, 0.25 ; \mathrm{KCl}, 0.2 ;\left(\mathrm{NH}_{4}\right)_{2} \mathrm{SO}_{4}, 0.1, \mathrm{pH}$ 6.8-7.0. One milliliter bacterial suspension was transferred to $250 \mathrm{ml}$ Erlenmeyer flask containing $80 \mathrm{ml}$ of the NBRIP broth medium and incubated for 7 days. A separate NBRIP broth medium inoculated with sterile Milli- $Q$ water served as the control treatment. The cultures were harvested by centrifugation at $10174 \mathrm{~g}$ for $10 \mathrm{~min}$ and soluble-P content of culture supernatant was estimated by the phosphomolybdate method (Murphy and Riley, 1962). The $\mathrm{pH}$ was determined with $\mathrm{pH}$ meter.

\section{Experimental designs}

\section{Plackett-Burman design}

Plackett-Burman design, a rapid screening multifactor to find the most significant independent factors (Plackett and Burman, 1946; Wang et al., 2007; Xiao et al., 2007), was used in the present study to screen the important variables that significantly influenced phosphate solubilization. In this study, a 12-run Plackett-Burman design (Table 1) with a first-order polynomial equation was applied to evaluate nine factors (including two dummy variables). Each variable was examined at two levels: -1 for the low level and +1 for the high level. The fitted first-order model is
$Y=\beta_{0}+\sum \beta_{i} x_{i}$

$Y$ is the predicted response, $\beta_{0}$ and $\beta_{i}$ are constant coefficients, and $x_{i}$ is the coded independent factors.

\section{Path of steepest ascent}

The method of steepest ascent is a procedure for moving along the direction of the maximum increase in the response ( $\mathrm{He}$ and Tan, 2006; Chen et al., 2009). The direction of steepest ascent is the direction in which the phosphate solubilization increases most rapidly by increasing or decreasing the values of the significant factors. The factors screened by the Plackett-Burman design were further optimized by this method. The path of steepest ascent was initiated from the center of the Plackett-Burman design. Experiments were performed along the steepest ascent path until the response did not increase any more. The experimental design and results of the steepest ascent method are shown in Table 3.

\section{Response surface methodology}

A central composite design (CCD) of RSM was employed to optimize the three most significant factors $\left(\left(\mathrm{NH}_{4}\right)_{2} \mathrm{SO}_{4}, \mathrm{Ca}_{3}\left(\mathrm{PO}_{4}\right)_{2}\right.$, $\mathrm{KCl})$ for enhancing $\mathrm{P}$ solubilization by $A$. calcoaceticus $\mathrm{YC}-5 \mathrm{a}$, screened by Plackett-Burman design. The three independent factors were investigated at five different coded levels $(-1.682,-1,0,+1$, +1.682 ) and the experimental design used for study is shown in Table 4. The variables were coded as in Equation 2:

$$
x_{i}=\left(X_{i}-m_{i}\right) / l_{i}, i=1,2, \ldots, k
$$

Where $X i$ is the real value of the independent variable; $x_{i}$ is the coded value; $m_{i}$ is the value of $X i$ at the center point and $l_{i}$ is the step change value. The phosphate solubilization was fitted using a second-order polynomial equation and a multiple regression of the data was carried out for obtaining an empirical model related to the most significant factors. The general form of the second-order polynomial equation is:

$Y=\beta_{0}+\sum \beta_{i} x_{i}+\sum \beta_{i i} x_{i}^{2}+\sum \beta_{i j} x_{i} x_{j}$

Where $Y$ is the predicted response, $x_{i}$ and $x_{j}$ are independent factors, 
Table 3. Experimental design and results of the steepest ascent path.

\begin{tabular}{ccccc}
\hline Run & $\left(\mathrm{NH}_{4}\right)_{\mathbf{2}} \mathbf{S O}_{\mathbf{4}}(\mathbf{g} / \mathbf{L})$ & $\mathrm{Ca}_{3}\left(\mathrm{PO}_{4}\right)_{2}(\mathbf{g} / \mathbf{L})$ & $\mathbf{K C l}(\mathbf{g} / \mathbf{L})$ & \multirow{2}{*}{$\begin{array}{c}\text { Soluble } \mathbf{P} \\
(\mathbf{m g} / \mathbf{L})\end{array}$} \\
\hline 1 & $\mathbf{X}_{2}$ & $\mathbf{X}_{3}$ & $\mathbf{X}_{\mathbf{7}}$ & \\
2 & 0.3 & 5 & 0.2 & 405.4 \\
3 & 0.24 & 6.5 & 0.24 & 427.7 \\
4 & 0.18 & 8 & 0.28 & 596.5 \\
5 & 0.12 & 9.5 & 0.32 & 675.3 \\
\hline
\end{tabular}

Table 4. Experimental design and results of the central composite design.

\begin{tabular}{|c|c|c|c|c|c|c|c|}
\hline \multirow{2}{*}{ Run } & \multicolumn{2}{|c|}{$\left(\mathrm{NH}_{4}\right)_{2} \mathrm{SO}_{4}(\mathrm{~g} / \mathrm{L})$} & \multicolumn{2}{|c|}{$\mathrm{Ca}_{3}\left(\mathrm{PO}_{4}\right)_{2}(\mathrm{~g} / \mathrm{L})$} & \multicolumn{2}{|c|}{$\mathrm{KCl}(\mathrm{g} / \mathrm{L})$} & \multirow{2}{*}{$\begin{array}{c}\text { Soluble P } \\
\mathrm{mg} / \mathrm{L}\end{array}$} \\
\hline & $x_{2}$ & $X_{2}$ & $x_{3}$ & $X_{3}$ & $x_{6}$ & $X_{6}$ & \\
\hline 1 & -1 & 0.06 & -1 & 8 & -1 & 0.28 & 624.87 \\
\hline 2 & 1 & 0.18 & -1 & 8 & -1 & 0.28 & 613.24 \\
\hline 3 & -1 & 0.06 & 1 & 11 & -1 & 0.28 & 736.76 \\
\hline 4 & 1 & 0.18 & 1 & 11 & -1 & 0.28 & 653.19 \\
\hline 5 & -1 & 0.06 & -1 & 8 & 1 & 0.36 & 619.36 \\
\hline 6 & 1 & 0.12 & -1 & 8 & 1 & 0.36 & 668.23 \\
\hline 7 & -1 & 0.06 & 1 & 11 & 1 & 0.36 & 739.67 \\
\hline 8 & 1 & 0.18 & 1 & 11 & 1 & 0.36 & 714.12 \\
\hline 9 & -1.682 & 0.02 & 0 & 9.5 & 0 & 0.32 & 668.26 \\
\hline 10 & 1.682 & 0.22 & 0 & 9.5 & 0 & 0.32 & 641.28 \\
\hline 11 & 0 & 0.12 & -1.682 & 6.977 & 0 & 0.32 & 587.16 \\
\hline 12 & 0 & 0.12 & 1.682 & 12.023 & 0 & 0.32 & 721.72 \\
\hline 13 & 0 & 0.12 & 0 & 9.5 & -1.682 & 0.25 & 635.81 \\
\hline 14 & 0 & 0.12 & 0 & 9.5 & 1.682 & 0.39 & 676.80 \\
\hline 15 & 0 & 0.12 & 0 & 9.5 & 0 & 0.32 & 672.74 \\
\hline 16 & 0 & 0.12 & 0 & 9.5 & 0 & 0.32 & 671.16 \\
\hline 17 & 0 & 0.12 & 0 & 9.5 & 0 & 0.32 & 677.57 \\
\hline 18 & 0 & 0.12 & 0 & 9.5 & 0 & 0.32 & 683.66 \\
\hline 19 & 0 & 0.12 & 0 & 9.5 & 0 & 0.32 & 681.03 \\
\hline 20 & 0 & 0.12 & 0 & 9.5 & 0 & 0.32 & 687.54 \\
\hline
\end{tabular}

$\beta_{0}$ is the intercept, $\beta_{i}$ is the linear coefficient, $\beta_{i i}$ is the quadratic coefficient, and $\beta_{i j}$ is the interaction coefficient.

\section{Statistical analysis}

Minitab 15.0 (Minitab Inc., Pennsylvania, USA) was used for the experimental designs and subsequent regressional analysis of the experimental data. Statistical analysis of the model was performed to evaluate the analysis of variance (ANOVA). The quality of the polynomial model equation was judged statistically by the coefficient of determination $\mathrm{R}^{2}$, and its statistical significance was determined by an $F$-test. The significance of the regression coefficients was tested by a $t$-test.

\section{RESULTS AND DISCUSSION}

\section{Plackett-Burman design}

The Plackett-Burman design is a rapid method for screening significant factors. Twelve runs were carried out to analyze the effect of 9 variables on $P$ solubilization and the results are demonstrated in Table 2. Analysis of the regression coefficients, $t$-values and $P$-values of 9 factors showed that $X_{1}, X_{3}, X_{5}, X_{6}, X_{7}$ and $X_{8}$ had positive effects on phosphate solubilization, whereas $X_{2}, X_{4}$ and $X_{9}$ had negative effects. The variable with $\mathrm{P}<0.05$ is considered as significant parameter. It was clear that variables $X_{2}, X_{3}$ and $X_{7}$ were the significant factors, while $X_{1}, X_{4}, X_{5}, X_{6}, X_{8}$ and $X_{9}$, with $P>0.05$, were considered insignificant and were not included in the next path of steepest ascent and CCD experiments. The model equation for phosphate solubilization $(\mathrm{Y})$ could be written as:

$$
\begin{aligned}
& Y=439.99+2.52 X_{1}-34.84 X_{2}+78.58 X_{3}-25.21 X_{4}+2.46 \\
& X_{5}+7.54 X_{6}+31.54 X_{7}+9.89 X_{8}-2.11 X_{9}
\end{aligned}
$$

The prominent effects of $\left(\mathrm{NH}_{4}\right)_{2} \mathrm{SO}_{4}\left(\mathrm{X}_{2}\right), \quad \mathrm{Ca}_{3}\left(\mathrm{PO}_{4}\right)_{2}\left(\mathrm{X}_{3}\right)$ 
Table 2. The Plackett-Burman design for screening variables in phosphate solubilization.

\begin{tabular}{|c|c|c|c|c|c|c|c|}
\hline \multirow{2}{*}{ Factors $(g / L)$} & \multirow{2}{*}{ Code } & \multicolumn{2}{|c|}{ Experimental value } & \multirow{2}{*}{ Effect } & \multirow{2}{*}{ Coef $^{*}$} & \multirow{2}{*}{$t$-value } & \multirow{2}{*}{ P-value } \\
\hline & & Low (-1) & High (+1) & & & & \\
\hline Intercept & & & & & 439.99 & 60.89 & 0.000 \\
\hline Glucose & $X_{1}$ & 10 & 15 & 5.05 & 2.52 & 0.35 & 0.76 \\
\hline$\left(\mathrm{NH}_{4}\right)_{2} \mathrm{SO}_{4}$ & $x_{2}$ & 0.1 & 0.3 & -69.68 & -34.84 & -4.82 & 0.040 \\
\hline $\mathrm{Ca}_{3}\left(\mathrm{PO}_{4}\right)_{2}$ & $x_{3}$ & 5 & 7.5 & 157.15 & 78.58 & 10.87 & 0.008 \\
\hline $\mathrm{MgCl}_{2} \cdot 6 \mathrm{H}_{2} \mathrm{O}$ & $X_{4}$ & 5 & 7.5 & -50.42 & -25.21 & -3.49 & 0.073 \\
\hline $\mathrm{MgSO}_{4} \cdot 7 \mathrm{H}_{2} \mathrm{O}$ & $X_{5}$ & 0.25 & 0.5 & 4.92 & 2.46 & 0.34 & 0.766 \\
\hline $\mathrm{NaCl}$ & $X_{6}$ & 0 & 0.2 & 15.08 & 7.54 & 1.04 & 0.406 \\
\hline $\mathrm{KCl}$ & $X_{7}$ & 0.2 & 0.4 & 63.08 & 31.54 & 4.37 & 0.049 \\
\hline $\mathrm{MnSO}_{4} \cdot \mathrm{H}_{2} \mathrm{O}$ & $X_{8}$ & 0 & 0.002 & 19.78 & 9.89 & 1.37 & 0.304 \\
\hline $\mathrm{FeSO}_{4} \cdot 7 \mathrm{H}_{2} \mathrm{O}$ & $X_{9}$ & 0 & 0.002 & -4.22 & -2.11 & -0.29 & 0.798 \\
\hline
\end{tabular}

$R^{2}=94.88 \%, R^{2}(\operatorname{adj})=91.82 \%,{ }^{*}$ Coef: coefficient

and $\mathrm{KCl}\left(\mathrm{X}_{7}\right)$ were likely due to the requirement of these medium components for phosphate solubilization. A critical $\mathrm{K}$ concentration is necessary for optimum solubilization rates (Beever and Burns, 1981; Illmer and Schinner, 1992).

\section{Path of steepest ascent}

Path of steepest ascent was based on the zero level of the Plackett-Burman design and moved along the direction in which $\left(\mathrm{NH}_{4}\right)_{2} \mathrm{SO}_{4}$ decreased and $\mathrm{Ca}_{3}\left(\mathrm{PO}_{4}\right)_{2}$, $\mathrm{KCl}$ increased. The experimental design and results were shown in Table 3. The highest response was $675.3 \mathrm{mg} / \mathrm{L}$ with $\left(\mathrm{NH}_{4}\right)_{2} \mathrm{SO}_{4} 0.12 \mathrm{~g} / \mathrm{L}, \mathrm{Ca}_{3}\left(\mathrm{PO}_{4}\right)_{2} 9.5 \mathrm{~g} / \mathrm{L}$ and $\mathrm{KCl} 0.32$ $\mathrm{g} / \mathrm{L}$. This point was concluded to be near the optimal point and was chosen for further optimization.

\section{Optimization by response surface methodology}

CCD was employed to study the interactions between the significant factors and also to determine their optimal levels. The design matrix of tested variables and the experimental results are represented in Table 4. Multiple regression analysis was used to analyze the data and thus a second-order polynomial equation was derived, as follows:

$Y=678.38-8.59 X_{2}+39.86 X_{3}+13.35 X_{7}-4.87 X_{2}^{2}-$ $4.98 X_{3}^{2}-4.32 X_{7}^{2}-18.29 X_{2} X_{3}+14.82 X_{2} X_{7}+1.79 X_{3} X_{7}$

The $t$-test and P-values were used to identify the effect of each factor on phosphate solubilization by $A$. calcoaceticus YC-5a (Table 5). A P-value of less than 0.05 indicates that the model terms are significant. In this case, $\left(\mathrm{NH}_{4}\right)_{2} \mathrm{SO}_{4}, \mathrm{Ca}_{3}\left(\mathrm{PO}_{4}\right)_{2}$ and $\mathrm{KCl}$ had a significant effect on phosphate solubilization, as well as the interaction terms. The fitness of the model was examined by the coefficient of determination $R^{2}$, which was found to be 0.9623 . A regression model having an $R^{2}$-value higher than 0.9 was considered as having a very high correlation (Chen et al., 2009). Therefore, the present $R^{2}$-value reflected a very good fit between the observed and predicted response. The adjusted determination coefficient $(R-S q=92.84 \%)$ was also satisfactory to confirm the significance of the model.

Furthermore, an analysis of variance (ANOVA) for the response surface quadratic model is presented in Table 6 , which also proves that this regression was statistically significant at $95 \%$ of confidence level. The model also showed statistically insignificant lack of fit $(P=0.053)$, so the model was supposed to be adequate for prediction within the range of variables employed. The response surface curves are plotted to explain the interaction of the variables and to determine the optimum level of each variable for maximum response. The response surface curves are shown in Figures 1 to 3 . Each figure demonstrated the effect of two factors while the other factors were fixed at zero level. The model predicted the optimal values (coded) of the three most significant variables were $X_{2}=1.339, X_{3}=2.320$ and $X_{7}=4.323$. Correspondingly, the values of $\left(\mathrm{NH}_{4}\right)_{2} \mathrm{SO}_{4}, \mathrm{Ca}_{3}\left(\mathrm{PO}_{4}\right)_{2}$ and $\mathrm{KCl}$ were $0.2,12.98$ and $0.49 \mathrm{~g} / \mathrm{L}$, respectively. The maximum predicted phosphate solubilization was $747.72 \mathrm{mg} / \mathrm{L}$.

\section{Validation of the model}

In order to confirm the optimized culture conditions, three additional experiments were performed using the predicted culture conditions. The mean values of phosphate solubilization was $743.5 \mathrm{mg} / \mathrm{L}$, which agreed well with the predicted value. This result demonstrates the validity of the response model.

\section{Conclusion}

Fractional factorial design and response surface 
Table 5. Regression coefficients and their significance for response surface model.

\begin{tabular}{ccccc}
\hline Term & Coef. & St. Dev. Coef. & $\mathbf{T}$ & $\mathbf{P}$ \\
\hline Constant & 678.38 & 4.45 & 152.397 & 0.000 \\
$\mathrm{X}_{2}$ & -8.59 & 2.95 & -2.908 & 0.016 \\
$\mathrm{X}_{3}$ & 39.86 & 2.95 & 13.496 & 0.000 \\
$\mathrm{X}_{7}$ & 13.35 & 2.95 & 4.519 & 0.001 \\
$\mathrm{X}_{2}{ }^{2}$ & -4.87 & 2.87 & -1.693 & 0.121 \\
$\mathrm{X}_{3}{ }^{2}$ & -4.98 & 2.87 & -1.733 & 0.114 \\
$\mathrm{X}_{7}{ }^{2}$ & -4.32 & 2.87 & -1.504 & 0.164 \\
$\mathrm{X}_{2} \mathrm{X}_{3}$ & -18.29 & 3.85 & -4.741 & 0.001 \\
$\mathrm{X}_{2} \mathrm{X}_{7}$ & 14.82 & 3.85 & 3.839 & 0.003 \\
$\mathrm{X}_{3} \mathrm{X}_{7}$ & 1.79 & 3.85 & 0.465 & 0.652 \\
\hline
\end{tabular}

$S=10.9144$, PRESS $=7761.46, \mathrm{R}-\mathrm{Sq}=96.23 \% ; \mathrm{R}-\mathrm{Sq}($ adjust $)=92.84 \%$.

Table 6. Analysis of variance (ANOVA) for the fitted quadratic polynomial model for optimization of $P$ solubilization.

\begin{tabular}{lcccccc}
\hline Source & DF $^{\mathbf{a}}$ & Seq. SS $^{\mathbf{b}}$ & Adj.SS & Adj. $\mathbf{M S}^{\mathbf{c}}$ & $\mathbf{F}$ & $\mathbf{P}$ \\
\hline Regression & 9 & 30405.2 & 30405.2 & 3378.35 & 28.36 & 0.000 \\
Linear & 3 & 25136.5 & 25136.5 & 8378.84 & 70.34 & 0.000 \\
Quadratic & 3 & 809.0 & 809.0 & 269.65 & 2.26 & 0.143 \\
Interactions & 3 & 4459.7 & 4459.7 & 1486.56 & 12.48 & 0.001 \\
Residual error & 10 & 1191.2 & 1191.2 & 119.12 & & \\
Lack of fit & 5 & 989.8 & 989.8 & 197.95 & 4.91 & 0.053 \\
Pure error & 5 & 201.5 & 201.5 & 40.30 & & \\
Total & 19 & 31596.4 & & & & \\
\hline
\end{tabular}

${ }^{a} \mathrm{DF}$, Degree of freedom, ${ }^{\mathrm{b}} \mathrm{SS}$, sum of squares, ${ }^{\mathrm{c}} \mathrm{MS}$, mean square.

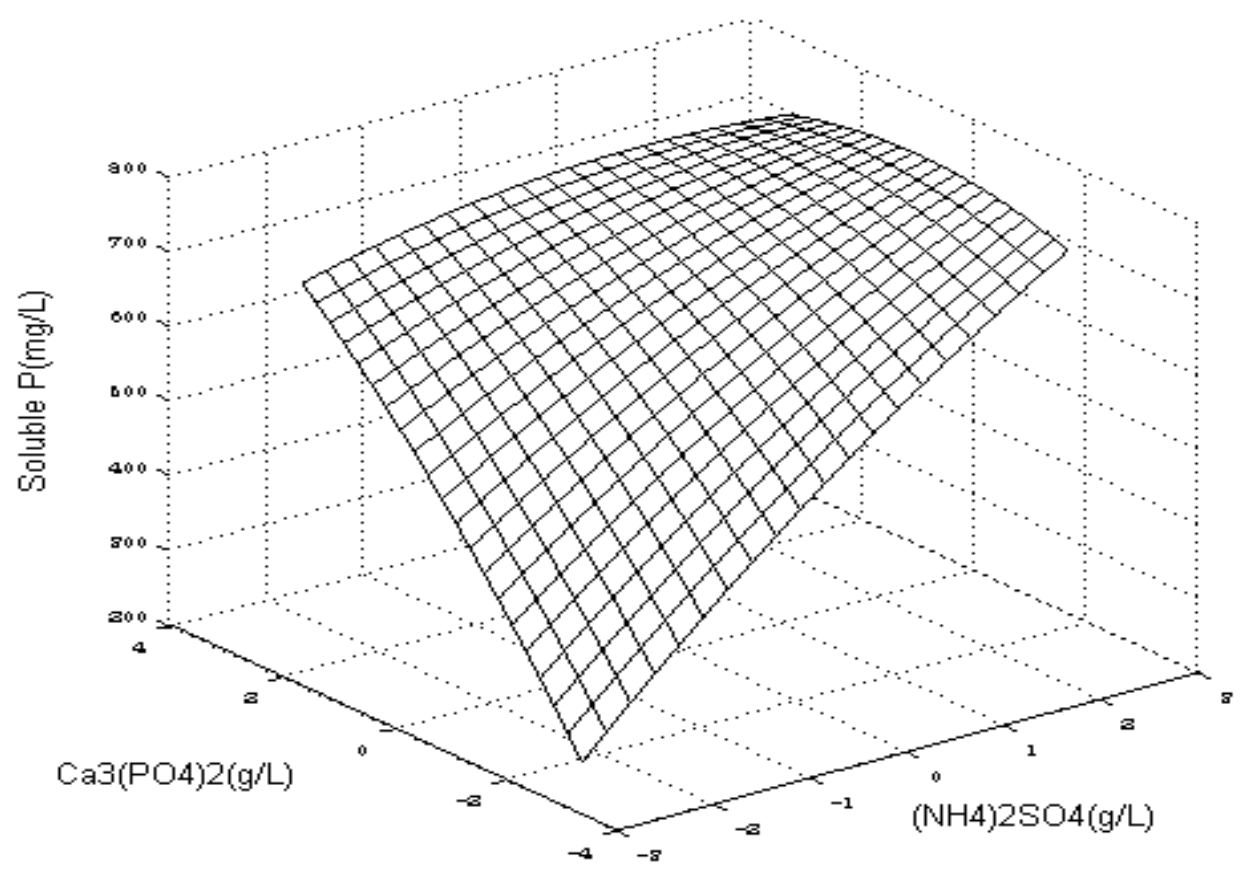

Figure 1. Response surface curve for phosphate solubilization by $A$. calcoaceticus $\mathrm{YC}-5 \mathrm{a}$ showing the interaction between $\left(\mathrm{NH}_{4}\right)_{2} \mathrm{SO}_{4}$ and $\mathrm{Ca}_{3}\left(\mathrm{PO}_{4}\right)_{2}$. 


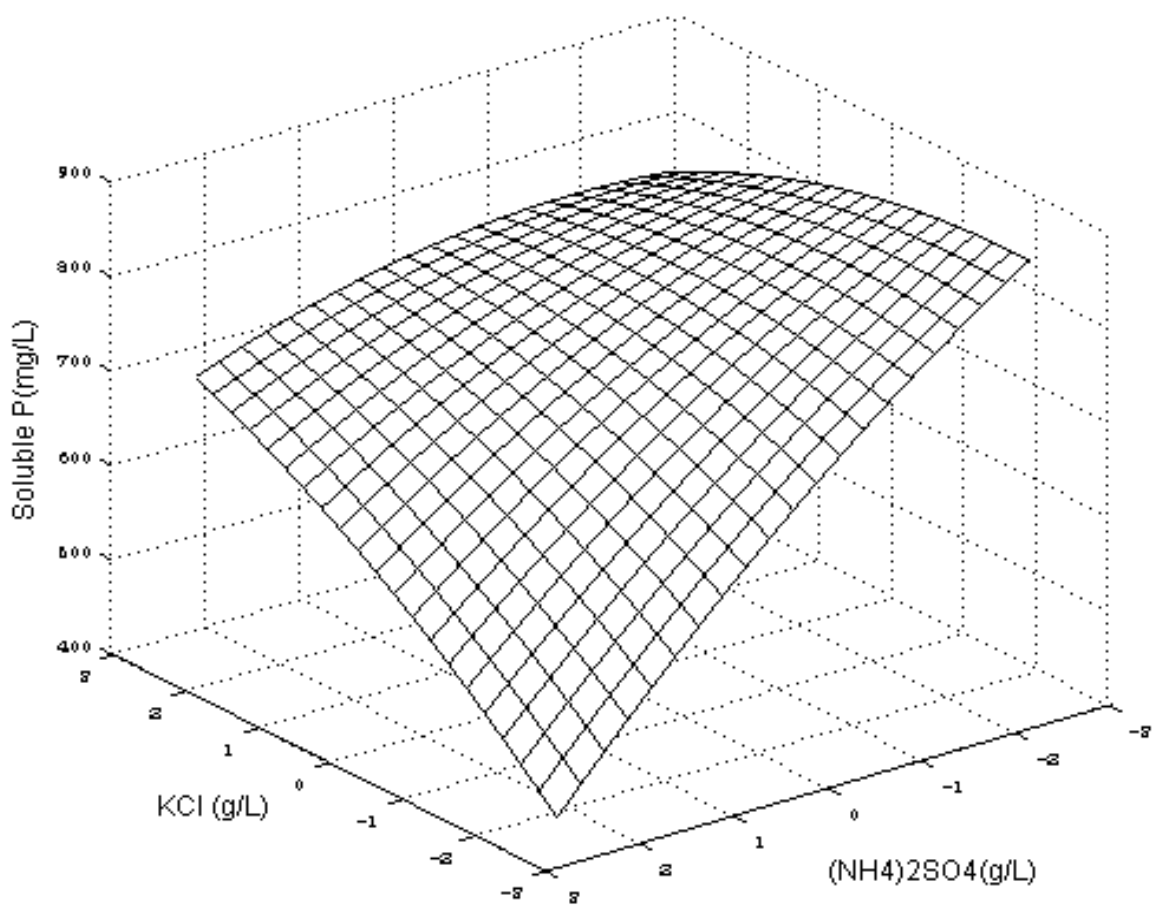

Figure 2. Response surface curve for phosphate solubilization by $A$. calcoaceticus $\mathrm{YC}-5 \mathrm{a}$ showing the interaction between $\left(\mathrm{NH}_{4}\right)_{2} \mathrm{SO}_{4}$ and $\mathrm{KCl}$.

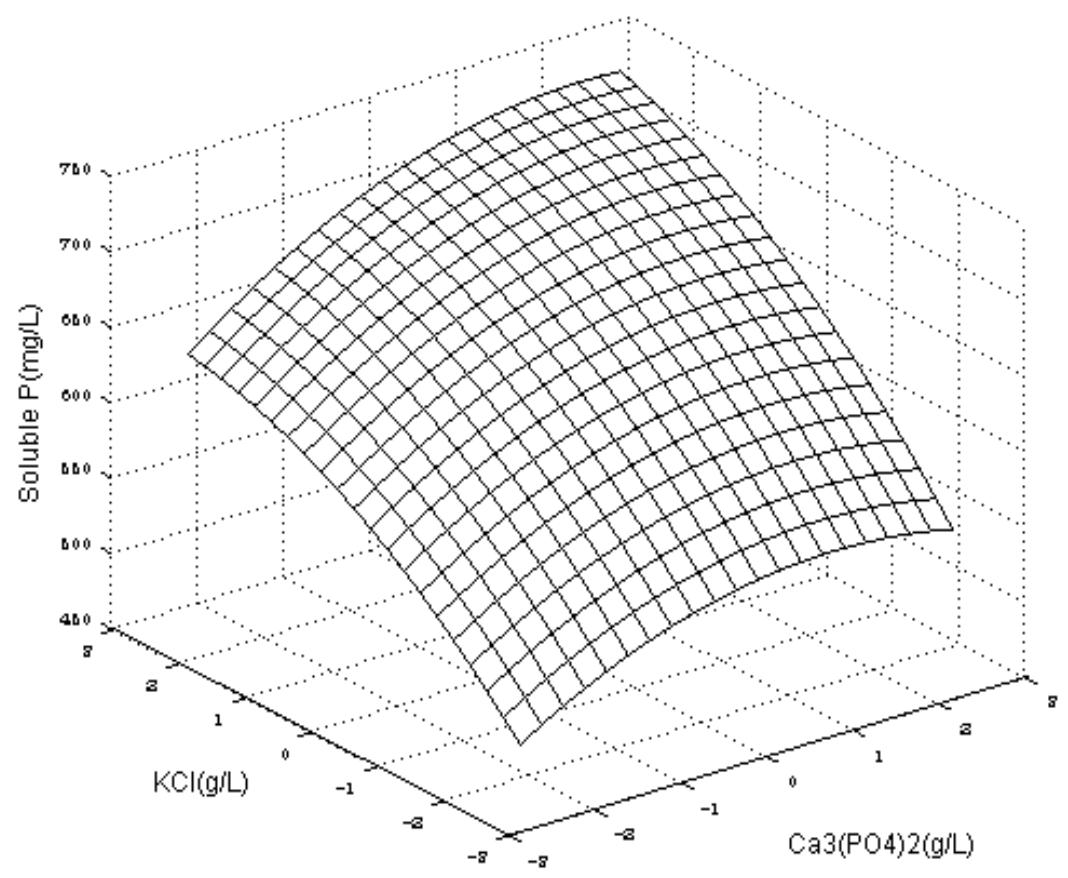

Figure 3. Response surface curve for phosphate solubilization by $A$. calcoaceticus $\mathrm{YC}-5 \mathrm{a}$ showing the interaction between $\mathrm{Ca}_{3}\left(\mathrm{PO}_{4}\right)_{2}$ and $\mathrm{KCl}$.

methodology had been proved to be effective on optimizing phosphate solubilization by $A$. calcoaceticus YC-5a. The final medium composition optimized was $(\mathrm{g} / \mathrm{L})$ : glucose, 10; $\quad\left(\mathrm{NH}_{4}\right)_{2} \mathrm{SO}_{4}, \quad 0.2 ; \quad \mathrm{Ca}_{3}\left(\mathrm{PO}_{4}\right)_{2}, \quad$ 12.98;
$\mathrm{MgCl}_{2} \cdot 6 \mathrm{H}_{2} \mathrm{O}, 5 ; \mathrm{MgSO}_{4} \cdot 7 \mathrm{H}_{2} \mathrm{O}, 0.25 ; \mathrm{KCl}, 0.49$ and initial $\mathrm{pH}, 6.8-7.0$, which resulted in an overall 1.8-fold increase compared with that using the original medium. Validation experiments were also carried out to verify the adequacy 
and the accuracy of the model, and the results showed that the predicted value agreed with the experimental values well.

\section{ACKNOWLEDGEMENTS}

This study was financially supported by the National High Technology Research and Development Program of China [grant number 2007AA03Z456].

\section{REFERENCES}

Beever RE, Burns D (1981). Phosphorus uptake, storage and utilization by fungi. Adv. Bot. Res., 8: 127-219

Chen XC, Bai JX, Cao JM, Li ZJ, Xiong J, Zhang L, Hong Y, Ying HJ (2009). Medium optimization for the production of cyclic adenosine 3', 5 '-monophosphate by Microbacterium sp. no. 205 using response surface methodology. Bioresour. Technol., 100: 919-924

Dey K (1988). Phosphate solubilizing organisms in improving fertility status. In Biofertilizers: Potentialities and Problems, pp. 237-248

Harris JN, New PB, Martin PM (2006). Laboratory tests can predict beneficial effects of phosphate-solubilising bacteria on plants. Soil Biol. Biochem., 38: 1521-1526

He YQ, Tan TW (2006). Use of response surface methodology to optimize culture medium for production of lipase with Candida sp. 99-125. J. Mol. Catal. B: Enzym., 43: 9-14

Illmer P, Schinner F (1992). Solubilization of inorganic phosphates by microorganisms isolated from forest soils. Soil Biol. Biochem., 24: 389-395

Kuklinsky-Sobral J, Araujo WL, Mendes R, Geraldi IO, Pizzirani-Kleiner AA, Azevedo JL (2004). Isolation and characterization of soybean-associated bacteria and their potential for plant growth promotion. Environ. Microbiol., 6: 1244-1251
Murphy J, Riley J (1962). A modified single solution method for the determination of phosphate in natural waters. Anal. Chim. Acta, 27: 31-36

Nautiyal C (1999). An efficient microbiological growth medium for screening phosphate solubilizing microorganisms. FEMS Microbiol.. Lett., 170: 265-270

Richardson A, Pankhurst C, Doube B, Gupta V, Grace P (1994). Soil microorganisms and phosphorus availability. Soil biota: management in sustainable farming systems: $50-62$

Rodriguez H, Fraga R (1999). Phosphate solubilizing bacteria and their role in plant growth promotion. Biotechnol. Adv., 17: 319-339

Wakelin SA, Gupta VVSR, Harvey PR, Ryder MH (2007). The effect of Penicillium fungi on plant growth and phosphorus mobilization in neutral to alkaline soils from southern Australia. Can. J. Microbiol., 53: 106-115

Wang X, Yin M, Xiao Z, Ma C, Lin Z, Wang PG, Xu P (2007). Production of uridine 5 '-monophosphate by Corynebacterium ammoniagenes ATCC 6872 using a statistically improved biocatalytic process. Appl. Microbiol. Biotechnol., 76: 321-328

Whitelaw M (1999). Growth promotion of plants inoculated with phosphate-solubilizing fungi. Adv. Agron., 69: 99-151

Xiao Z, Liu P, Qin J, Xu P (2007). Statistical optimization of medium components for enhanced acetoin production from molasses and soybean meal hydrolysate. Appl. Microbiol. Biotechnol., 74: 61-68.

Perez E, Sulbaran M, Ball MM, Yarzabal LA (2007). Isolation and characterization of mineral phosphate-solubilizing bacteria naturally colonizing a limonitic crust in the south-eastern Venezuelan region. Soil Biol. Biochem., 39: 2905-2914

Plackett RL, Burman JP (1946). The design of optimum multifactorial experiments. Biometrika, 33: 305-325. 